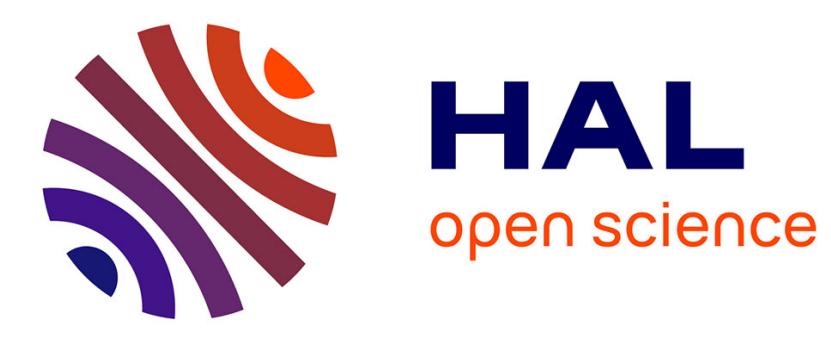

\title{
Stark shift of the absorption spectra in Ge/Ge1-xSnx/Ge type-I single QW cell for mid-wavelength infra-red modulators
}

N. Yahyaoui, N. Sfina, J.-L. Lazzari, A. Bournel, M. Said

\section{- To cite this version:}

N. Yahyaoui, N. Sfina, J.-L. Lazzari, A. Bournel, M. Said. Stark shift of the absorption spectra in Ge/Ge1-xSnx/Ge type-I single QW cell for mid-wavelength infra-red modulators. Superlattices and Microstructures, 2015, 85, pp.629-637. 10.1016/j.spmi.2015.06.021 . hal-03144282

\author{
HAL Id: hal-03144282 \\ https://hal.science/hal-03144282
}

Submitted on 17 Feb 2021

HAL is a multi-disciplinary open access archive for the deposit and dissemination of scientific research documents, whether they are published or not. The documents may come from teaching and research institutions in France or abroad, or from public or private research centers.
L'archive ouverte pluridisciplinaire HAL, est destinée au dépôt et à la diffusion de documents scientifiques de niveau recherche, publiés ou non, émanant des établissements d'enseignement et de recherche français ou étrangers, des laboratoires publics ou privés. 


\section{Accepted Manuscript}

Stark shift of the absorption spectra in $\mathrm{Ge} / \mathrm{Ge}_{1-\mathrm{x}} \mathrm{Sn}_{\mathrm{x}} / \mathrm{Ge}$ type-I single $\mathrm{QW}$ cell for Mid-Wavelength Infra-Red modulators

N. Yahyaoui, N. Sfina, J.-L. Lazzari, A. Bournel, M. Said

PII:

S0749-6036(15)30044-6

DOI: http://dx.doi.org/10.1016/j.spmi.2015.06.021

Reference: YSPMI 3830

To appear in:

Superlattices and Microstructures

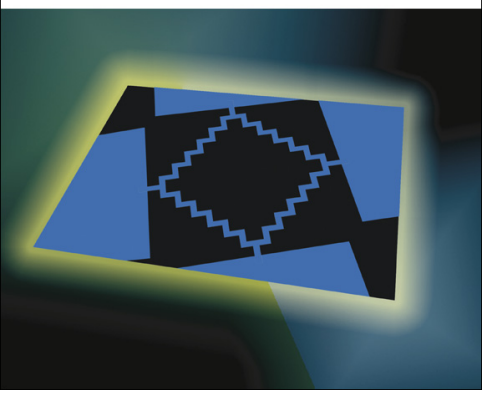

Received Date:

15 April 2015

Revised Date:

15 June 2015

Accepted Date:

17 June 2015

Please cite this article as: N. Yahyaoui, N. Sfina, J.-L. Lazzari, A. Bournel, M. Said, Stark shift of the absorption spectra in $\mathrm{Ge} / \mathrm{Ge}_{1-\mathrm{x}} \mathrm{Sn}_{\mathrm{x}} / \mathrm{Ge}$ type-I single QW cell for Mid-Wavelength Infra-Red modulators, Superlattices and Microstructures (2015), doi: http://dx.doi.org/10.1016/j.spmi.2015.06.021

This is a PDF file of an unedited manuscript that has been accepted for publication. As a service to our customers we are providing this early version of the manuscript. The manuscript will undergo copyediting, typesetting, and review of the resulting proof before it is published in its final form. Please note that during the production process errors may be discovered which could affect the content, and all legal disclaimers that apply to the journal pertain. 


\title{
Stark shift of the absorption spectra in $\mathrm{Ge} / \mathrm{Ge}_{1-\mathrm{x}} \mathrm{Sn}_{\mathrm{x}} / \mathrm{Ge}$ type-I single $\mathrm{QW}$ cell for Mid-Wavelength Infra-Red modulators
}

\author{
N. Yahyaoui ${ }^{1 *}, N$. Sfina ${ }^{l, a}$, J.-L. Lazzari ${ }^{2}$, A. Bournel ${ }^{3}$, and M. Said ${ }^{1 *}$ \\ ${ }^{1}$ Laboratoire de la Matière Condensée et des Nanosciences (LMCN), Département de Physique, Faculté \\ des Sciences de Monastir, Avenue de l'Environnement, 5019 Monastir, Tunisia. \\ ${ }^{2}$ Aix-Marseille Université, CNRS, CINaM UMR 7325, Case 913, Campus de Luminy, 13288 Marseille \\ cedex 9, France. \\ ${ }^{3}$ Institut d'Électronique Fondamentale (IEF), UMR 8622 CNRS - Université Paris-Sud, Bât. 220, 91405 \\ Orsay cedex, France. \\ ${ }^{a}$ Faculty of science and art KKU Mahail Assir, king Kaled university Saoudi arabia.
}

*Corresponding authors: Moncef Said moncef_said@yahoo.fr \& Naima Yahyaoui naima.yahyaoui@yahoo.fr

\begin{abstract}
For mid-wavelength infra-red (MWIR) modulation or detection applications, we propose $\alpha$-Sn rich $\mathrm{Ge} / \mathrm{Ge}_{1-\mathrm{x}} \mathrm{Sn}_{\mathrm{x}} / \mathrm{Ge}$ a type-I single quantum wells (SQW) partially strain compensated on $\mathrm{Ge}_{1-\mathrm{y}} \mathrm{Sn}_{\mathrm{y}}$ relaxed layers grown onto (001)-oriented Ge substrate. Such elementary cells with $W$-like potential profiles of conduction and valence bands have been modeled by solving the one-dimensional Schrödinger equation under an applied external electrical field. First, strain effects on electrons, heavy holes (hh) and light holes (lh) energy bands for strained/relaxed $\mathrm{Ge}_{1-\mathrm{x}} \mathrm{Sn}_{\mathrm{x}} / \mathrm{Ge}_{1-\mathrm{y}} \mathrm{Sn}_{\mathrm{y}}$ heterointerfaces are investigated using the modelsolid theory in the whole ranges $(0 \leq x, y \leq 1)$ of Sn compositions. From the obtained band-discontinuities, band gaps and effective masses, $\mathrm{Ge}_{1-\mathrm{y}} \mathrm{Sn}_{\mathrm{y}} / \mathrm{Ge} / \mathrm{Ge}_{0.80} \mathrm{Sn}_{0.20} / \mathrm{Ge} / \mathrm{Ge}_{1-\mathrm{y}} \mathrm{Sn}_{\mathrm{y}}$ cells are computed as a function of the $\mathrm{Ge}_{0.80} \mathrm{Sn}_{0.20}$ well width for three compositions of the $\mathrm{Ge}_{1-\mathrm{y}} \mathrm{Sn}_{\mathrm{y}}$ buffer layer ( $\mathrm{y}=0.05,0.07$ and 0.09 ) in order to get the optimum quantum confinement of electrons and holes levels while keeping a reasonable amount of averaged strain in the cell. The electric field effect on the absorption spectra is given. An absorption coefficient in the $6 \times$ to $3 \times 10^{3} \mathrm{~cm}^{-1}$ range is reasonably obtained for a SQW at room temperature with a rather large Stark shift of the direct transition between 0.46 and $0.38 \mathrm{eV}$ (i.e., $\lambda=3.26-$ $2.70 \mu \mathrm{m})$ at large external fields $(50 \mathrm{kV} / \mathrm{cm})$. These characteristics are attractive for the design of MWIR optical modulators.
\end{abstract}

Keywords: quantum well, absorption spectra, quantum-confined Stark effect, mid-wave infrared optical modulators 


\section{Introduction}

Recently, the most reports on the different transceiver components have been focused on the traditional telecommunication wavelength bands around $1.3 \mu \mathrm{m}$ and $1.55 \mu \mathrm{m}$. In fact, the military systems of monitoring or detection require the use of detectors with long wavelength [1, 2]. In this connection, several groups have been exploring the use of silicon photonics into the mid-wave infrared (MWIR). In the last two years, the germanium-tin (GeSn) cubic alloy draws a considerable research attention for developing new Si-based photonic devices [3-6]. It offers alternative routes for band gap and strain engineering in a silicon compatible technology because of tunable band gaps in the mid-infrared [7] and possibility of high electron and hole mobility [8]. The heterodevices from those materials can overcome limitations imposed by the indirect band gap of Si and Ge. The direct band gap of $\alpha$-Sn-based group-IV was predicted in 1993 by Soref [9]. Based on this prediction, high-quality binary GeSn and ternary SiGeSn alloys with high $\mathrm{Sn}$ composition have been considered as promising materials for optoelectronic applications [10, 11]. Offering the possibility of absorption in near and mid-infrared range, they may be useful in modulators [12], and detectors [13-15]. Guo-En Chang et al. proposed in a recent paper a polarization-insensitive waveguide modulator at $1.55 \mu \mathrm{m}$ using a Ge/SiGeSn multiple-quantumwells (MQW) structure and analyzed its operation at room-temperature [16]. By increasing the amount of $\alpha-S n$ in the GeSn alloy composition, the direct bandgap decreases, which is of interest in long-wavelength Si technology applications, such as for infrared detectors and long-wave integrated optoelectronics [17]. Therefore, previous studies demonstrate that the alloys SnGealloy-based asymmetric double QW structure with large $\alpha$-Sn content for MWIR modulators provides interesting polarization properties. To achieve good performance, this is likely to be based on a simple rectangular potential well profile [18].

In this work, the parameters of such a SQW structure in the $\mathrm{Ge} / \mathrm{Ge}_{1-\mathrm{x}} \mathrm{Sn}_{\mathrm{x}} / \mathrm{Ge}$ system are optimized over a relaxed $\mathrm{Ge}_{1-\mathrm{y}} \mathrm{Sn}_{\mathrm{y}}$ layer. In a first step toward the calculation of optical properties of GeSn SQW, the band offsets of strained $\mathrm{Ge}_{1-x} \mathrm{Sn}_{x}$ on (001)-oriented $\mathrm{Ge}_{1-\mathrm{y}} \mathrm{Sn}_{\mathrm{y}}$ are determined. Then, the potential profile and the subband energies of $\mathrm{Ge}_{0.80} \mathrm{Sn}_{0.20}$ QWs are computed using the effective mass theory. In these calculations, a condition of partial strain-compensation is considered for layers. The achieved results showed that the proposed SQW has a $W$-like type-I band alignment, a close energy for $\Gamma$ transition in the GeSn QW and an improved quantum confinement in both conduction and valence bands. Finally, the effect of the electric field on the absorption spectrum at room temperature is presented and discussed. 


\section{Calculation of material parameters}

The electronic band parameters, gaps and discontinuities modified by the strain field are the key tools in order to perform an accurate simulation of the optoelectronic properties of strained $\mathrm{Ge}_{1-x} \mathrm{Sn}_{x}$ and relaxed $\mathrm{Ge}_{1-y} \mathrm{Sn}_{y}$ mid-infrared optical modulators. To explore and exploit these properties, it is necessary to know the band discontinuities at interfaces constituting the heterostructure. With this aim, we have adopted the procedure we outlined in Ref [19]. The valence band offset at $\mathrm{Ge}_{1-x} \mathrm{Sn}_{x} / \mathrm{Ge}_{1-y} \mathrm{Sn}_{y}$ heterointerface are expressed as:

$$
\begin{aligned}
& \Delta E_{v, h h, l h}=E_{v, h h, l h}^{s t r}-E_{v, h h, l h}^{u n s}=\Delta E_{v}^{u n s}+\delta E_{v, h h, l h}^{s h}+\delta E_{v, h h, l h}^{h y} \\
& \Delta E_{C}=E_{C}^{s t r}-E_{C}^{u n s}=\Delta E_{v}^{u n s}+\Delta E_{g}^{u n s}+\delta E_{C}^{s h}+\delta E_{C}^{h y}
\end{aligned}
$$

where $\Delta E_{v}^{u n s}$ is the natural valence band discontinuity, $\Delta E_{g}^{u n s}$ is the band gap difference, $\delta E_{C, v}^{s h}$ and $\delta E_{C, v}^{h y}$ are the band energy shift for the valence and the conduction bands under uniaxial and hydrostatic strain respectively:

$$
\begin{aligned}
& \delta E_{c}^{h y}=a_{c}\left(2 \varepsilon_{/ /}+\varepsilon_{\perp}\right) \\
& \delta E_{v}^{h y}=a_{v}\left(2 \varepsilon_{/ /}+\varepsilon_{\perp}\right)
\end{aligned}
$$

Here $\mathrm{a}_{\mathrm{v}}$ and $\mathrm{a}_{\mathrm{c}}$ are the hydrostatic deformation potentials for the valence and conduction bands. and $\varepsilon_{/ /}$are $\varepsilon_{\perp}$ the strain components tensor respectively in-plane and perpendicular to the plane interface. $\varepsilon_{/ /}$is expressed in terms of the substrate and the over layer lattice constants and $a$ such that

$$
\begin{aligned}
& \varepsilon_{/ /}=\frac{\mathrm{a}_{/ /}}{\mathrm{a}}-1 \\
& \varepsilon_{\perp}=\frac{\mathrm{a}_{\perp}}{\mathrm{a}}-1=-2 \frac{\mathrm{C}_{12}}{\mathrm{C}_{11}} \varepsilon_{/ /}
\end{aligned}
$$

where $C_{11}$ and $C_{12}$ are the elastic constants of the epitaxial layer material. The shear contribution joined to the spin-orbit interaction leads to an additional splitting of the valence band.

For (001) interface, the energy shifts from the band relative to their unstrained positions are given by [20]

$$
\begin{aligned}
& \delta E_{v, h h}^{s h}=-\frac{1}{2} \delta E_{001} \\
& \delta E_{v, l h}^{s h}=-\frac{\Delta_{0}}{2}+\frac{1}{4} \delta E_{001}+\frac{1}{2}\left[\Delta_{0}^{2}+\Delta_{0} \delta E_{001}+\frac{9}{4}\left(\delta E_{001}\right)^{2}\right]^{1 / 2}
\end{aligned}
$$




$$
\begin{aligned}
& \delta E_{v, s o}^{s h}=+\frac{\Delta_{0}}{2}+\frac{1}{4} \delta E_{001}-\frac{1}{2}\left[\Delta_{0}^{2}+\Delta_{0} \delta E_{001}+\frac{9}{4}\left(\delta E_{001}\right)^{2}\right]^{1 / 2} \\
& \delta \mathrm{E}_{001}=2 \mathrm{~b}\left(\varepsilon_{\perp}-\varepsilon_{/ /}\right)=-2 \mathrm{~b} \varepsilon_{/ /}\left(2 \frac{\mathrm{C}_{12}}{\mathrm{C}_{11}}+1\right)
\end{aligned}
$$

where $b$ represents the uniaxial deformation potential for the valence band, and is the spin-orbit splitting. The subscripts hh and lh refer to the heavy hole and the light hole bands, respectively.

We note that the bandgap energy for the alloy $\mathrm{Ge}_{\mathrm{x}} \mathrm{Sn}_{\mathrm{x}}$ is taken from our calculations in [21]. All the other parameters for the $\mathrm{Ge}_{1-x} \mathrm{Sn}_{x}$ material systems are calculated using a simple linear interpolation between Ge, and $\alpha$-Sn, whose values are taken form references [22-24] and summarized in Table 1. Using the above set of equations, we have calculated the band offsets between the $\mathrm{Ge}_{1-x} \mathrm{Sn}_{x}$ strained layer and the (001)-oriented relaxed $\mathrm{Ge}_{1-y} \mathrm{Sn}_{y}$ substrate. The approximate analytical expression for the conduction and valence bands discontinuities between strain splitting valleys as a function of $\mathrm{x}$ and $\mathrm{y}$ compositions are given below in electron volts $(\mathrm{eV})$ :

$$
\begin{aligned}
& \Delta E_{C}{ }^{\Gamma}=(x-y)[1.243+(-1.816+0.641 x)(1+0.167(y+x))] \\
& \Delta E_{C}{ }^{L}=(x-y)[0.284+(-0.34+0.264 x)(1+0.167(y+x))] \\
& \Delta E_{h h}=(x-y)[0.856+(1.168+0.824 x)(1+0.167(y+x))] \\
& \Delta E_{l h}=(x-y)[0.49+(0.273+0.762 x)(1+0.167(y+x))]
\end{aligned}
$$

\section{Experimental challenge of the proposed structure}

Our (001)-oriented heterostructure is composed by $\mathrm{Sn}$-rich $\mathrm{Ge}_{1-\mathrm{x}} \mathrm{Sn}_{\mathrm{x}} \mathrm{QW}$ (x=0.20) of thickness $L_{w}$ separated by two Ge barrier of thickness $L_{b}$; the whole stack being embedded between relaxed $\mathrm{Ge}_{1-\mathrm{y}} \mathrm{Sn}_{\mathrm{y}}$ pseudo substrate with an $\alpha$-Sn content 5, 7 and 9\%. Assuming a compositional linear dependence of the lattice parameter (Vegard's law), the large mismatch between $\mathrm{Ge}_{0.80} \mathrm{Sn}_{0.20}$ and $\mathrm{Ge}\left(\varepsilon_{w} \sim 2.9 \%\right)$ is reduced to $\varepsilon_{w} \sim 2.2,1.9$ and $1.6 \%$ for $\mathrm{y}=5,7$ and $9 \%$, respectively. Correlatively, the tensile strain $\varepsilon_{b}$ of Ge barriers rises from $-0.7 \%,-1.0 \%$ and $1.3 \%$. For such lattice mismatches, the critical thickness for formation of dislocations calculated with the pessimistic 'energetic equilibrium' model early given by F. C. Frank and J. H. van der Merwe [25] ranges from 2.5, 3.0, to $3.6 \mathrm{~nm}$ and 8.2, 5.8, to $4.4 \mathrm{~nm}$ respectively for $\mathrm{Ge}_{0.80} \mathrm{Sn}_{0.20}$ and Ge. It is worth to note that the law given by J. W. Matthews and A. E. Blakeslee [26] gives 
6 to 7 times higher values of the critical thickness in better agreement with those experimentally observed for the $\mathrm{SiGe} / \mathrm{Si}$ system for an average temperature of deposition in the $500-900^{\circ} \mathrm{C}$ range. This makes realistic the epitaxial growth of defect-free individual layers while the whole stack obeys a partial strain-compensation upon the thicknesses and compositions of the well and barrier. The following law for full strain compensation can be derived from the strain-thickness model given by N. J. Ekins-Daukes et al. [27]

$$
\frac{L_{w}}{2 L_{b}} \frac{\sigma_{w}}{\sigma_{b}}=\frac{\varepsilon_{b}}{\varepsilon_{w}} \cong \frac{y}{x-y}
$$

where $\sigma_{001}=\left(C_{11}-C_{12}\right)\left(2 \frac{C_{12}}{C_{11}}+1\right) V_{m}$ is the elastic deformation parameter of the $\mathrm{Ge}_{1-\mathrm{x}} \mathrm{Sn}_{\mathrm{x}}$ well and Ge barrier layers, and $\mathrm{V}_{\mathrm{m}}$ is the molar volume.

In principle, the growth of Sn-rich bulk GeSn alloys is limited by the maximum solubility of $1.1 \%$ at $400^{\circ} \mathrm{C}$ [28] or the poor thermal stability of richer alloys [29-30]. But it has been proved that the metastable miscibility gap could be largely reduced ( $20 \%$ in composition) for $\mathrm{Ga}_{1-\mathrm{x}} \mathrm{In}_{\mathrm{x}} \mathrm{As}_{\mathrm{y}} \mathrm{Sb}_{1-\mathrm{y}} / \mathrm{GaSb}$ by taking into account the $\sigma . \varepsilon^{2}$ strain energy [31]. Moreover, the authors showed that the spinodal decomposition could be suppressed for those alloys having compositions nearly lattice-matched to that of the substrate lattice and they achieved layers with compositions in metastable region by Liquid Phase Epitaxy, a nearly equilibrium technique. These thermodynamic limitations can better be overcome using highly non equilibrium conditions (low pressure, low temperature, high growth rate, surfactant mediated growth) allowed by modern epitaxial technique such as Molecular Beam Epitaxy (MBE), Reduced Pressure Chemical Vapor Deposition (RP-CVD), Ultra High Vacuum - CVD (UHV-CVD), Plasma Enhanced - CVD (PE-CVD), Pulsed Laser Induced Epitaxy (PLIE), or Atomic Layer Deposition / Epitaxy (ALD/ALE). Indeed, B. Vincent et al [32] show that metastable GeSn epitaxial growth on Ge substrate with Sn content up to $8 \%$ using Atmospheric Pressure - Chemical Vapor Deposition (AP-CVD). Besides, they have proved that reduced pressure is definitely not the key mandatory factor for growing Sn-rich GeSn alloys. Furthermore, it should be remember that the thermodynamic solubility and stability are defined for large monocrystals. Taking into account the additional surface energy, they may increase with decreasing the size (thickness). Finally, we can assume that the metastable state of $\mathrm{Sn}$-rich $\mathrm{Ge}_{1-\mathrm{x}} \mathrm{Sn}_{\mathrm{x}}$ - rich layer under compressive stress sandwiched between two layers of Ge stable under tensile stress is maintained.

Hence, the compressive and tensile strain states of the layers and their thicknesses as well partial strain compensation are not solely a way to design and manipulate the quantum level and 
wave functions in such heterostructure, but they allow engineering its experimental feasibility itself.

\section{Absorption spectrum: modeling and results}

A schematic diagram of the proposed structure is shown in Figure 1. The computation of the wave functions and the electron and heavy hole confinement energies for this SQW has been carried out by solving Schrödinger equation in the effective mass approximation [33] and by varying the thickness $L_{w}$ for three different $\alpha$-Sn compositions in the substrates and keeping $\mathrm{L}_{\mathrm{b}}=7 \mathrm{~nm}$. Due to the large band-offset and both large electrons and holes confinement energies in such a W-like type-I single QW cell, we assumed the parabolic effective mass approximation with uncoupled energy bands. Typically, the fundamental interband transition is more likely in quantum wells. For this reason, the optimization should result in the determination of the final set of parameters that gives the best quantum confinement for electron and heavy holes quantum levels.

In Figure 2, we have illustrated the electron (plot a) and hole confinement energies (plot b) and the detection energy of the fundamental transition (plot $\mathrm{c}$ ) as a function of the $\mathrm{Ge}_{0.80} \mathrm{Sn}_{0.20}$ well width $L_{w}$ for $y=0.05$ (solid line), $y=0.07$ (dashed line) and $y=0.09$ (dotted line). It is seen that the quantum confinement energies increase when the well thickness $L_{w}$ of the $\mathrm{Ge}_{0.80} \mathrm{Sn}_{0.20}$ layer is larger but decreases with the increase of $\alpha$-Sn composition $y$ in the substrate. Accordingly, as shown in Figure 2(c), the detection energy (resp. wavelength) for the fundamental transitions decreases (rep. increases) as the GeSn well width increases and the $\alpha$-Sn composition y in the substrate decreases.

Another characteristic of an electron transition is the oscillator strength. It is defined from an initial state $\left|\Psi_{i}\right\rangle$ to a finite state $\left|\Psi_{f}\right\rangle$ by the expression

$f_{i \rightarrow f}=\left.\frac{2 m_{0}}{\hbar^{2}}\left(E_{i}-E_{f}\right)\left\langle\Psi_{i}|z| \Psi_{f}\right\rangle\right|^{2}$

where $m_{0}$ is the free electron mass, $\hbar$ is the Plank constant, $\left(E_{i}-E_{f}\right)$ is the energy difference between the two states and $\left\langle\Psi_{i}|z| \Psi_{f}\right\rangle$ is the dipole matrix element of the fundamental transition. We have calculated the oscillator strengths of the interband electron-hole transition of our designs versus the GeSn QW thickness for different $\alpha$-Sn compositions $y$ in the substrates using Eq. (15). The results are depicted in Figure 3. It is seen that the oscillator strength increases when the well width is larger, in respect with the increase of the overlaps of the electron and hole wavefunctions. 
Using the above results, we have simulated the SQW structure based on a $10 \mathrm{~nm}$-large $\mathrm{Ge}_{0.80} \mathrm{Sn}_{0.20}$ QW separated by $7 \mathrm{~nm}$ Ge thick barriers embedded in relaxed $\mathrm{Ge}_{0.95} \mathrm{Sn}_{0.05}$ layer. The proposed stack is designed in a pragmatic way for a pseudomorphic growth on relaxed $\mathrm{Ge}_{0.95} \mathrm{Sn}_{0.05}$ assuming individual layer thickness being smaller than the known critical thickness [34]. Indeed, the compositions of the well and substrate ensure a type-I band alignment, high enough quantum confinement for both electrons and hole, and a close energy $\square \Gamma$ bandgap. Moreover, recent investigations have made possible to achieve strained GeSn with large $\alpha$-Sn content [35, 36]. Figure 4 shows simulation of the band diagram, hole and electron wave functions for a $10 \mathrm{~nm} \mathrm{Ge}{ }_{0.80} \mathrm{Sn}_{0.20} \mathrm{QW}$ with Ge barriers on relaxed $\mathrm{Ge}_{0.95} \mathrm{Sn}_{0.05}$ in the absence of an electric field. According to the band alignment calculation, both the conduction band minimum and valence band maximum are located in the well region. So, this heterostructure has an important type-I alignment for the necessary interband optical transitions.

In order to comprehend quantum-confined Stark effect in the Ge/Ge ${ }_{0.80} \mathrm{Sn}_{0.20} \mathrm{SQW}$ strained on relaxed $\mathrm{Ge}_{0.95} \mathrm{Sn}_{0.05}$, we have investigated the influence of a constant external electric field $\mathrm{F}_{\mathrm{z}}$ on the energy levels. This leads to external field-dependence solutions of the energies for all subbands and their related wave functions. Self-consistent resolution of the Schrödinger and Poisson equation could be done [20] but this is not done in the present work. Figure 5 shows the detection energy (and wavelengths) for the interband transition series consisting $\mathrm{hh}_{\mathrm{n}}-\mathrm{c} \Gamma_{1}, \mathrm{lh}(\mathrm{n}=1$ and $\mathrm{n}=2$ ) as a function of applied electric field, ranging from 0 to $50 \mathrm{kV} / \mathrm{cm}$ at room temperature. In the absence of an electric field, we can see that the $\mathrm{hh}_{1}-\mathrm{c} \Gamma_{1}$ transition energy between the first states of electron $\left(\mathrm{c}_{1}\right)$ and heavy hole $\left(\mathrm{hh}_{1}\right)$ is $460 \mathrm{meV}(2.7 \mu \mathrm{m})$. We note also that the other transitions occur at a lower wavelength $(<2.7 \mu \mathrm{m})$. These transition energies decrease with the increase of the electric field. This shift results from the combination of strain and quantum confinement effects.

Then, we calculated the electric-field dependence of the absorption coefficient in SQW structures as explained below. The dispersions of the absorption coefficient are obtained from the imaginary part of the dielectric constant, respectively in the estimation of the free-carrier contribution, energy and polarization-dependent momentum matrix elements and line broadening represented by a Gaussian line shape function taken into account. The contributions of free-carrier-transitions to the imaginary part may be written [37]:

$$
\alpha(\hbar \omega)=\frac{e^{2}}{\varepsilon_{0} m_{0}^{2} L_{e f f}} \frac{m_{e h}}{\Pi \hbar^{2}} \sum_{i} \sum_{j}\left|M_{b}\right|^{2}\left|\int \Psi_{e i}(z) \Psi_{h j}(z) d z\right|^{2} \int M(E) F\left(E+E_{g}+E_{e i}+E_{h j}-\hbar \omega\right) d E
$$

Here $L_{e f f}$ is the overall thickness of the $Q W, m_{e h}$ is the reduced hole effective mass $E_{g}, E_{e i}$ and $E_{h j}$ are the energy gap, and the quantized energies of the $\mathrm{i}$ electron and $\mathrm{j}$ hole, respectively, and 
denotes the photon energy. The energies $\mathrm{E}_{\mathrm{ei}}$ and $\mathrm{E}_{\mathrm{hj}}$, and the related wave functions, $\Psi_{e i}(z)$ and $\Psi_{h j}(z)$, are solutions of the one-dimensional Schrödinger equations for the QW subjected to the electric field [38]. The quantity $\left|M_{b}\right|^{2}$ is the average matrix element for the Bloch state [39] given by

$$
\left|M_{b}\right|^{2}=\frac{m_{0}^{2} E_{g}\left(E_{g}+\Delta\right)}{12 m_{e}\left(E_{g}+\frac{2}{3} \Delta\right)}
$$

In which $m_{e}$ is the electron effective mass and $\Delta$ is the spin orbit split-off energy.

In Eq. (16), $F\left(\hbar \omega_{0}-\hbar \omega\right)$ is the Gaussian line shape function defined as:

$$
F\left(\hbar \omega_{0}-\hbar \omega\right)=\frac{1}{\sqrt{\Pi \delta}} \exp \left[-\left(\hbar \omega_{0}-\hbar \omega\right)^{2} / \delta^{2}\right]
$$

with $\hbar \omega_{0}=E+E_{g}+E_{e i}+E_{h j}$ and $\delta=\frac{h}{\tau(\ln 2)^{-1 / 2}}$

where $\tau$ is the interband relaxation time. The energy dependence of the energy-and polarization dependent transition matrix elements [37] are given by the following equations

$$
\begin{aligned}
& M(E)=\frac{3}{4}\left(1+\cos ^{2} \theta\right)=\frac{3}{4}\left(1+\frac{E_{e i}+E_{h j}}{E_{e i}+E_{h j}+E}\right) \\
& M(E)=\frac{1}{4}\left(5-3 \cos ^{2} \theta\right)=\frac{1}{4}\left(5-3 \frac{E_{e i}+E_{h j}}{E_{e i}+E_{h j}+E}\right)
\end{aligned}
$$

for electron to heavy and light hole transitions, respectively, where $\theta$ is the angle of the electron wave vector with respect to the $z$ axis (normal to the well plan). The polarization is assumed to be parallel to the plan of the layers (TE-mode).

Figure 6 shows the absorption spectra due to the direct interband transitions for the type-I $\mathrm{Ge} / \mathrm{Ge}_{0.80} \mathrm{Sn}_{0.20}$ QW strained on relaxed $\mathrm{Ge}_{0.95} \mathrm{Sn}_{0.05}$ under different electric fields at room temperature. At zero electric field, the $\mathrm{hh}_{1}-\mathrm{c} \Gamma_{1}$ absorption peak is situated at $2.7 \mu \mathrm{m}$. When the electric field is increased, the $\mathrm{hh}_{1}-\mathrm{c} \Gamma_{1}$ absorption peak is shifted towards larger wavelengths and the absorption edge is gradually attenuated. At an electric field of $50 \mathrm{kV} / \mathrm{cm}$, the energy for the $\mathrm{hh}_{1}-\mathrm{c} \Gamma_{1}$ reduces to $3.26 \mu \mathrm{m}(0.38 \mathrm{eV})$. Note the absorption spectrum is obtained considering transition between independent conduction band states and valence states. In low-dimensional structure, electron-hole interaction plays an important role in determining the optical transition. In particular for quantum wells, a strong electron-hole interaction should enhance absorption at $\Gamma$ critical point. Thus the relative intensities of absorption coefficients ( $\Gamma$ vs. L) given in Figure 6 describe more or less the experimental results of reference [40]. Our results of absorption coefficient value in the modeled system, about $6 \times 10^{3} \mathrm{~cm}^{-1}$ in the wavelength $2.6 \mu \mathrm{m}$ at zero bias, 
is comparable to those of the Gabriela et al [41] photodetectors. The absorption coefficient in the latter InGaAs/InAlAs detectors is about $5 \times 10^{3} \mathrm{~cm}^{-1}$ for the wavelength $1.55 \mu \mathrm{m}$ at $300 \mathrm{~K}$ and about $6 \times 10^{4} \mathrm{~cm}^{-1}$ for uncooled photodetectors based on $\mathrm{HgCdTe}$ for the wavelength $10.6 \mu \mathrm{m}$ at room temperature [42]. So, the progress in the GeSn crystal growth and their high iconicity compared to III-V compounds make of them a very attractive family.

\section{Conclusion}

In conclusion, we have theoretically studied a type I SQW structure based on a $\mathrm{Ge}_{0.80} \mathrm{Sn}_{0.20}$ layer separated by Ge barriers as active stack for mid-infrared absorber. Our calculations were deduced from the solution of the Schrodinger equation without and with applied electric field. The explored band structure parameters of strained $\mathrm{Ge}_{1-\mathrm{x}} \mathrm{Sn}_{\mathrm{x}}$ are useful tools for optoelectronic applications. Specifically, the band offsets of strained $\mathrm{Ge}_{1-x} \mathrm{Sn}_{x}$ and relaxed $\mathrm{Ge}_{1-y} \mathrm{Sn}_{y}$ are determined. The absorption spectra as well as the detection energies dependency on the applied electric field from zero up to $50 \mathrm{kV} / \mathrm{cm}$ have been investigated at room temperature. A strong absorption coefficient $\left(>1 \times 10^{3} \mathrm{~cm}^{-1}\right)$ and a Stark shift of the direct transition between $2.7 \mu \mathrm{m}$ and $3.26 \mu \mathrm{m}$ are also demonstrated in the present work. These results show the large potential of strained $\mathrm{Ge}_{1-\mathrm{x}} \mathrm{Sn}_{\mathrm{x}} / \mathrm{Ge}_{1-y} \mathrm{Sn}_{y} \mathrm{SQW}$ structure, for example, to achieve high performance electroabsorption modulators not only for all telecommunication windows but also for mid-wave infrared applications. 


\section{References}

[1] G. Roelkens, U. Dave, A. Gassenq, N. Hattasan, and W. J. Green, IEEE J. Sel. Top. Quantum Electron. 20(4) (2014) 8201511.

[2] D. J. Thomson, L. Shen, J. J. Ackert, E. Huante-Ceron, A. P. Knights, M. Nedeljkovic, A. C. Peacock, and G. Z. Mashanovich, Opt. Express 22 (2014) 10825.

[3] J. Kouvetakis, J. Menendez, and A. V. G. Chizmeshya, Annu. Rev. Mater. Res. 36, 497 (2006).

[4] G. Sun, R. A. Soref, and H. H. Cheng, J. Appl. Phys. 108 (2010) 033107.

[5] G. Sun, R. Soref, and H. H. Cheng, Opt. Express 18 (2010) 19957.

[6] G. E. Chang, S. W. Chang, and S. L. Chuang, IEEE J. Quantum Electron. 46 (2010) 1813.

[7] G. He and H. A. Atwater, Phys. Rev. Lett. 79 (1997) 1937.

[8] J. D. Sau and M. L. Cohen, Phys. Rev. B 75 (2007) 045208.

[9] R. A. Soref, L. Friedman, Superlattices Microstruct. 14 (1993) 189.

[10] I. S. Yu, T. H. Wu, K. Y. Wu, H. H. Cheng, V. I. Mashanov, A. I. Nikiforov, O. P. Pchelyakov, and X. S. Wu, AIP Adv. 1 (2011) 042118.

[11] Alexander A. Tonkikh, Christian Eisenschmidt, Vadim G. Talalaev, Nikolay D. Zakharov, Joerg Schilling, Georg Schmidt, and Peter Werner, Appl. Phys. Lett. 103 (2013) 032106.

[12] P. Moontragoon, N. Vukmirovic, Z. Ikonic, and P. Harrison, IEEE J. Sel. Topics Quantum Electron. $16(2010) 100$.

[13] J. Mathews, R. Roucka, J. Xie, S.-Q. Yu, J. Menéndez, and J. Kouvetakis, Appl. Phys. Lett. 95 (2009) 133506.

[14] J. Werner, M. Oehme, M. Schmid, M. Kaschel, A. Schirmer, E. Kasper, and J. Schulze, Appl. Phys. Lett. 98 (2011) 061108.

[15] S. Su, B. Cheng, C. Xue, W. Wang, Q. Cao, H. Xue, W. Hu, G. Zhang, Y. Zuo, and Q. Wang, Opt. Exp. 19 (2011) 6400.

[16] Guo-En Chang and Chia-Ou Chang, IEEE. 48 (2012) 533.

[17] R. A. Soref, Proc. SPIE, 6898 (2008) 689809.

[18] J. Thalken, W. Li, S. Haas, and A. F. J. Levi, Appl. Phys. Lett. 85 (2004) 121.

[19] N. Yahyaoui, N. Sfina, J.-L. Lazzari, A. Bournel, and M. Said, Eur. Phys. J. B 86 (2013) 259.

[20] F. Ben Zid, A. Bouri, H. Mejri, R. Tlili, M. Said, F. A. D’Avitaya, J. Derrien, J. Appl. Phys. 91 (2002) 9170.

[21] N. Yahyaoui, N. Sfina, J.-L. Lazzari, A. Bournel, and M. Said, J. Appl. Phys. 115 (2014) 033109.

[22] W. J. Yin, X. G. Gong, and S. H. Wei, Phys. Rev. B 78 (2008) 16120.

[23] S. S. Chang, and S. L. Chuang, IEEE J. Quantum Electron. 43 (2007) 249.

[24] S. Gupta, B. M. Köpe, Y. Nishi, and K. C. Saraswat, J. Appl. Phys. 113 (2013) 073707.

[25] F. C. Frank and J. H. van der Merwe, Proc. Roy. Soc. (London) A 198 (1949) 216.

[26] J. W. Matthews and A. E. Blakeslee, J. Cryst. Growth 27 (1974) 118.

[27] N. J. Ekins-Daukes, K. Kawaguchi, and J. Zhang, Crystal Growth Design. 2(4) (2002) 287. 
[28] R. W. Olesinski and G. J. Abbaschian, The Ge-Sn (Germanium-Tin) system, Bulletin of Alloy Phase Diagrams, Volume 5, Issue 3, June 1984, pp 265-271.

[29] G. He and H. A. Atwater, Appl. Phys. Lett. 68 (1996) 664.

[30] O. Gurdal, P. Desjardins, J. R. A. Carlsson, N. Taylor, H. H. Radamson, J.-E. Sundgren, and J. E. Greene, J. Appl. Phys. 83 (1998) 162.

[31] J.-L. Lazzari, E. Tournié, F. Pitard, A. Joullié, and B. Lambert, Growth limitations by the miscibility gap in the liquid phase epitaxy of GaInAsSb on GaSb, Materials Sciences and Engineering B9, 19 (1991) 125.

[32] B. Vincent, F. Gencarelli, H. Bender, C. Merckling, B. Douhard, D. H. Petersen, O. Hansen, H. H. Henrichsen, J. Meersschaut, W. Vandervorst, M. Heyns, R. Loo, and M. Caymax, Appl. Phys. Lett. 99 (2011) 152103.

[33] N. Yahyaoui, N. Sfina, S. Abdi-Ben Nasrallah, J.-L. Lazzari, and M. Said, Comput. Phys. Commun. 185 (2014) 3119.

[34] N. Sfina, J. Lazzari, J. Derrien, F. A. D’Avitaya, and M. Said, Eur. Phys. J. B 48 (2005) 151.

[35] S. Wirths et al Appl. Phys. Lett. 102 (2013) 192103.

[36] K. Zelazna, M. P. Polak, P. Scharoch, J. Serafinczuk, M. Gladysiewicz, J. Misiewicz, J. Dekoster, and R. Kudrawiec Appl. Phys. Lett. 106 (2015) 142102.

[37] M. Yamanishi and I. Suemune, Jpn. J. Appl. Phys. 23 (1984) 35.

[38] Y. Kan, M. Yamanishi, Y. Usami, and I. Suemune, IEEE J. Quantum Electron 22 (1986) 1837.

[39] Heterostructure Lasers, Part A. New York: Academic, ch. 3, 6 (1978) 150.

[40] A. Gassenq, F. Gencarelli, J. Van Campenhout, Y. Shimura, R. Loo, G. Narcy, B. Vincent, and G. Roelkens, Optics Express 20 (2012) 27297.

[41] G. Livescu, D. A. B.Miller, D. S. Chemla, M. Ramaswany, T. Y. Chang, N. Sauer, A. C. Gossard, and J. H. English, IEEE journal of Quantum electronics 24 (1988) 1677.

[42] K. Moazzami, J. Phillips, D. Lee, S. Krishnamurthy, G. Benoit, Y. Fink, and Tiwald, Journal of Electronic Materials 34 (2005) 773. 


\section{Figure captions}

Figure 1: Band diagram of the $\mathrm{Ge} / \mathrm{Ge}_{0.80} \mathrm{Sn}_{0.20} / \mathrm{Ge} \mathrm{QW}$ on relaxed $\mathrm{Ge}_{1-\mathrm{y}} \mathrm{Sn}_{\mathrm{y}}(\mathrm{y}=0.05,0.07$ and $0.09)$.

Figure 2: (a) Electron and (b) heavy hole confinement-energies for the $\mathrm{Ge} / \mathrm{Ge}_{0.80} \mathrm{Sn}_{0.20} / \mathrm{Ge} \mathrm{QW}$ on relaxed $\mathrm{Ge}_{1-\mathrm{y}} \mathrm{Sn}_{\mathrm{y}}$ as a function of the QW width for $\mathrm{y}=0.05$ (plain line), $\mathrm{y}=0.07$ (dashed line) and $y=0.09$ (dash-dotted line). (c) Corresponding detection energies of the fundamental transition at room temperature. The Ge barrier width is $\mathrm{L}_{b}=7 \mathrm{~nm}$. According to Eq. (15), strain compensation is obtained for $\mathrm{L}_{\mathrm{w}}=4.7,7.5$ and $11.4 \mathrm{~nm}$, respectively.

Figure 3: Oscillator strength of the fundamental transition of the $\mathrm{Ge} / \mathrm{Ge}_{0.80} \mathrm{Sn}_{0.20} / \mathrm{Ge} \mathrm{QW}$ on relaxed $\mathrm{Ge}_{1-\mathrm{y}} \mathrm{Sn}_{\mathrm{y}}$ versus the GeSn QW width for $\mathrm{y}=0.05$ (plain line), $\mathrm{y}=0.07$ (dashed line) and $\mathrm{y}$ $=0.09$ (dash-dotted line). The Ge barrier width is $\mathrm{L}_{\mathrm{b}}=7 \mathrm{~nm}$.

Figure 4: Band alignment, wave functions, and energy levels for electrons, heavy holes (blue color) and light holes (red color) for the $\mathrm{Ge} / \mathrm{Ge}_{0.80} \mathrm{Sn}_{0.20} / \mathrm{Ge}$ strained $\mathrm{QW}$ on relaxed $\mathrm{Ge}_{0.95} \mathrm{Sn}_{0.05}$ $\left(\mathrm{L}_{\mathrm{w}}=10 \mathrm{~nm}, \mathrm{~L}_{\mathrm{b}}=7 \mathrm{~nm}\right)$. The origin of energy is taken at the bottom of the GeSn QW.

Figure 5: Evolution of the detection energies of $h h_{n}-c \Gamma_{1}$ and $l h-c \Gamma_{1}(n=1$ and $n=2)$ transitions of $7 \mathrm{~nm}-\mathrm{Ge} / 10 \mathrm{~nm}-\mathrm{Ge}_{0.80} \mathrm{Sn}_{0.20} / 7 \mathrm{~nm}-\mathrm{Ge} \mathrm{QW}$ strained on relaxed $\mathrm{Ge}_{0.95} \mathrm{Sn}_{0.05}$ versus applied electrical field.

Figure 6: Room temperature theoretical absorption coefficient spectra of $7 \mathrm{~nm}-\mathrm{Ge} / 10 \mathrm{~nm}-$ $\mathrm{Ge}_{0.80} \mathrm{Sn}_{0.20} / 7 \mathrm{~nm}-\mathrm{Ge} \mathrm{QW}$ strained on (001)-oriented relaxed $\mathrm{Ge}_{0.95} \mathrm{Sn}_{0.05}$ versus applied electric field. 


\section{Table captions}

Table 1: Ge and $\alpha$-Sn band parameters at Room temperature used in the present work. 
Figure 1

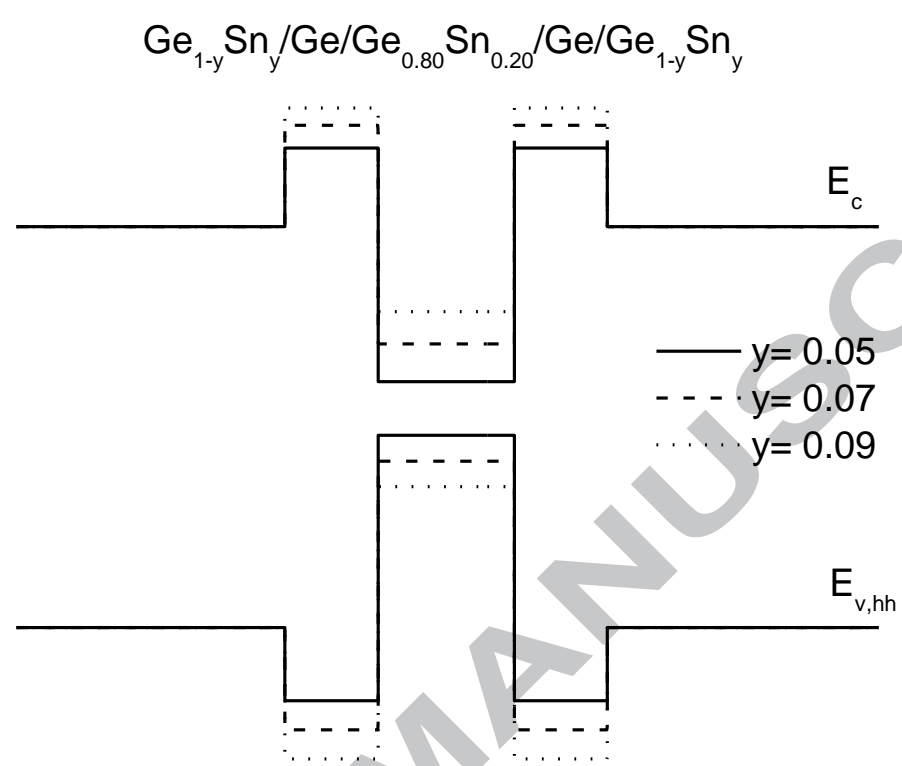




\section{Figure 2}
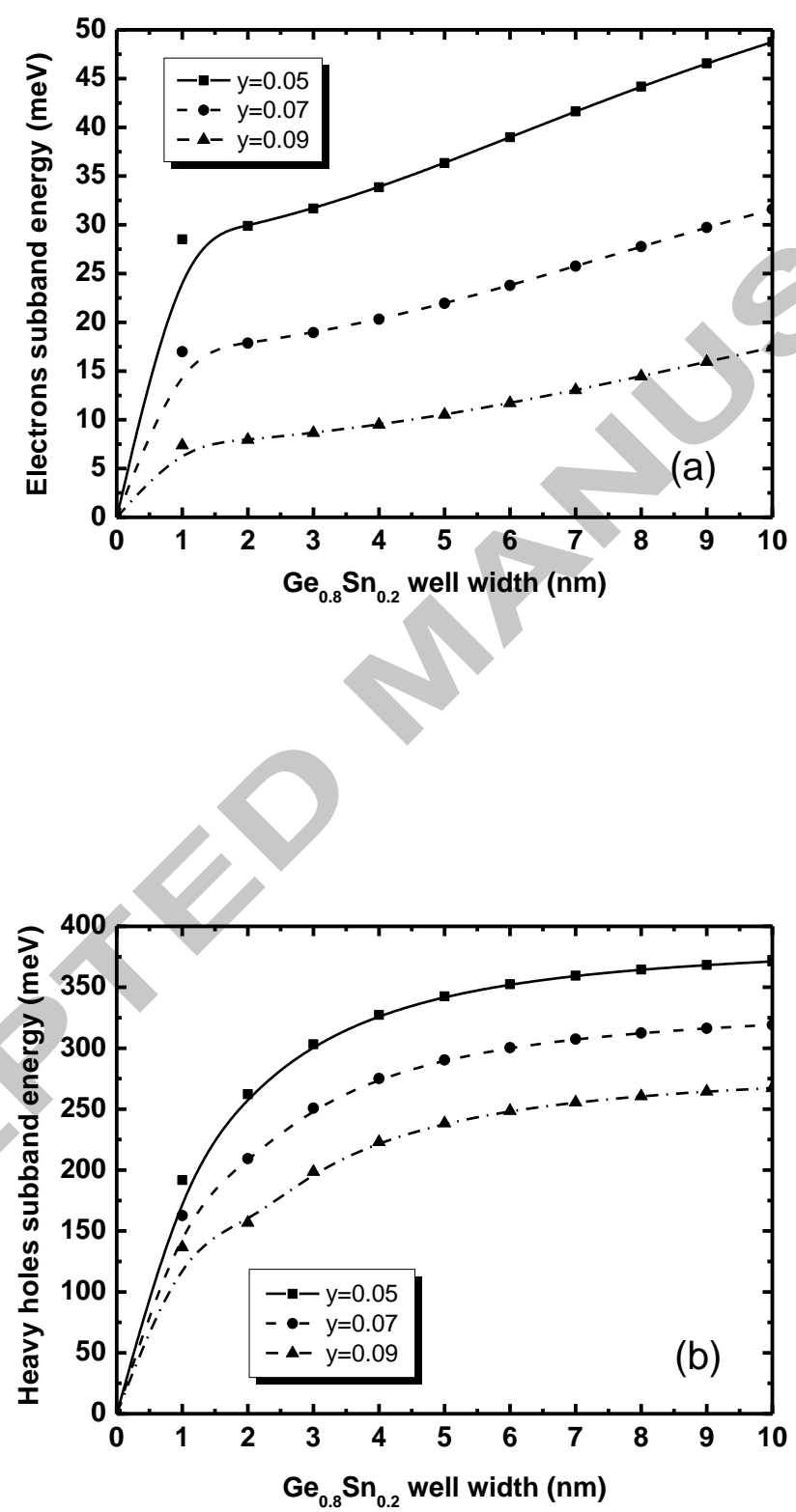


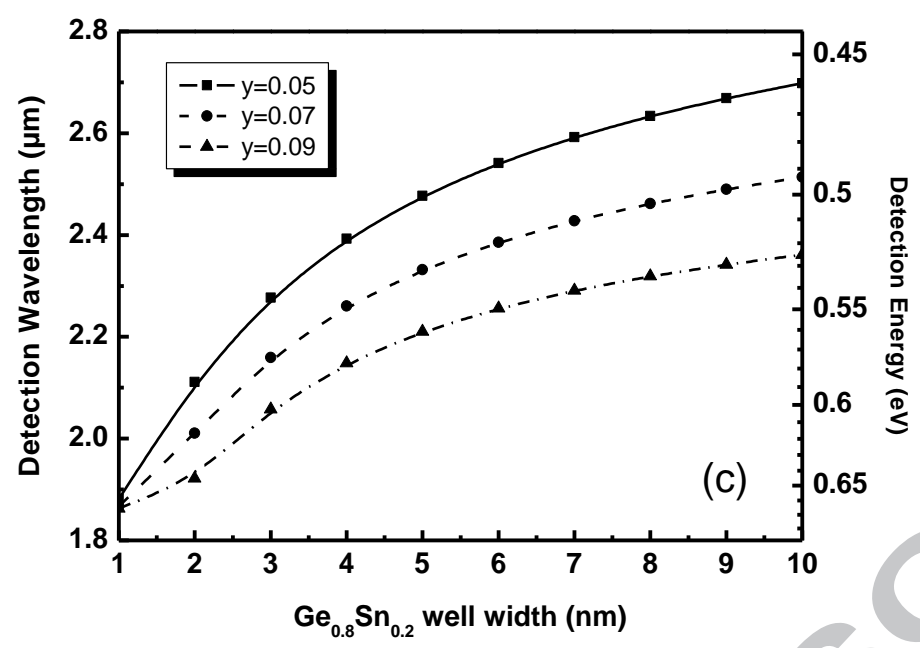

Figure 3

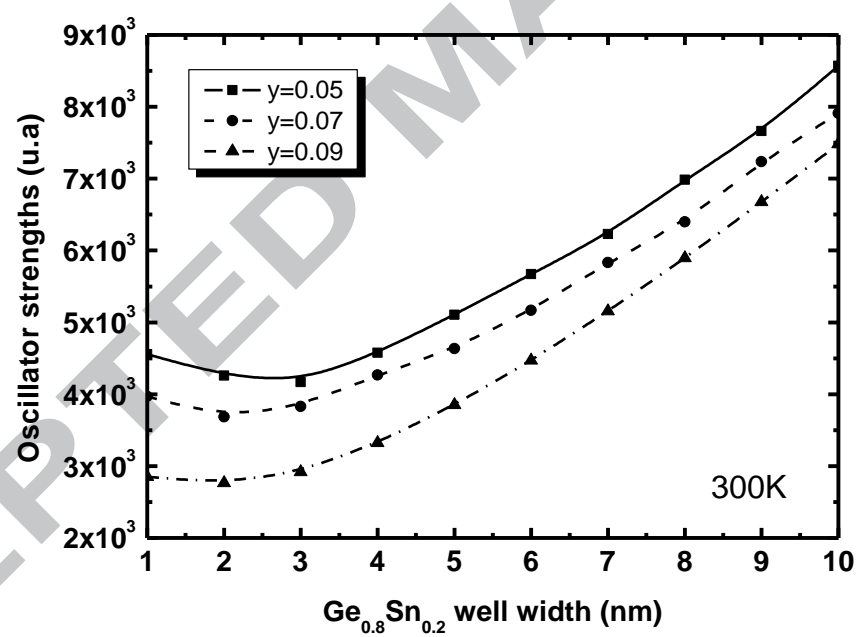

$\underline{\text { Figure } 4}$ 


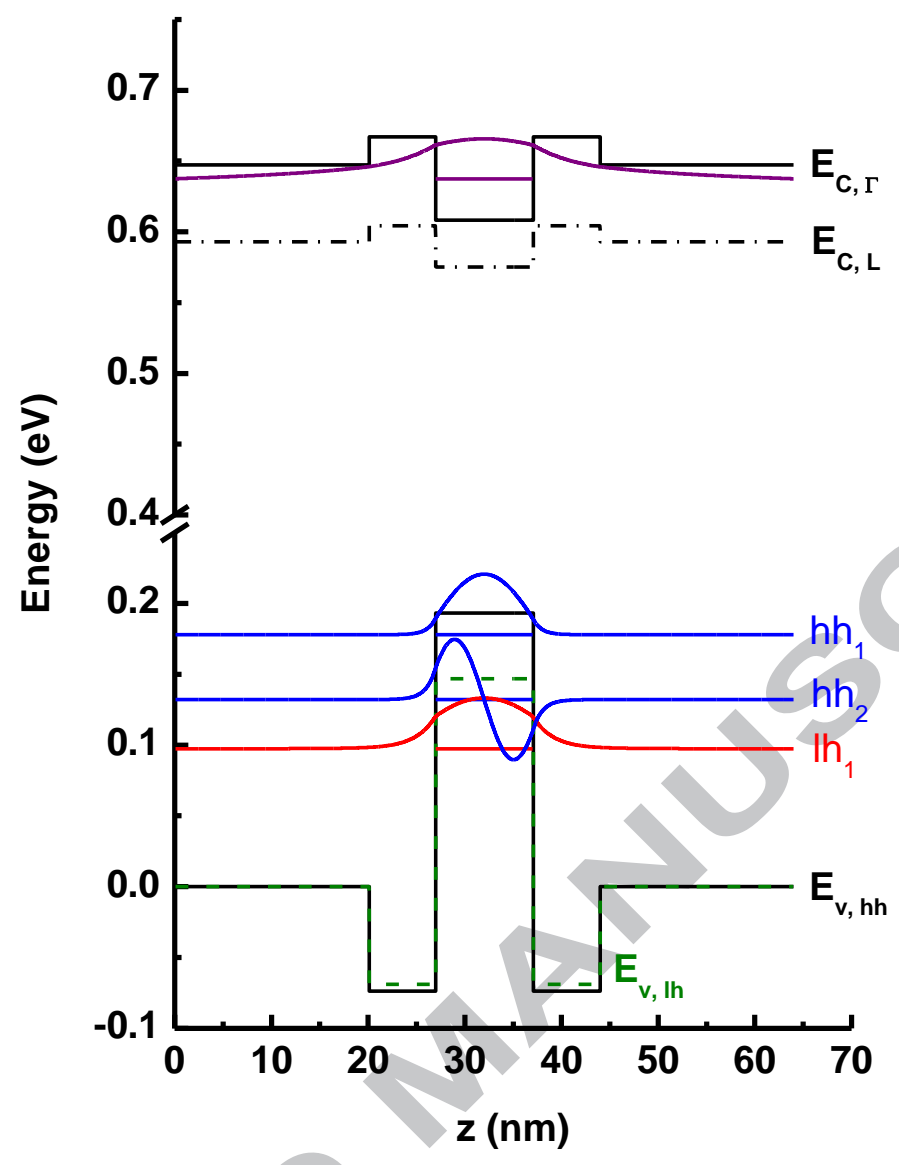


$\underline{\text { Figure } 5}$

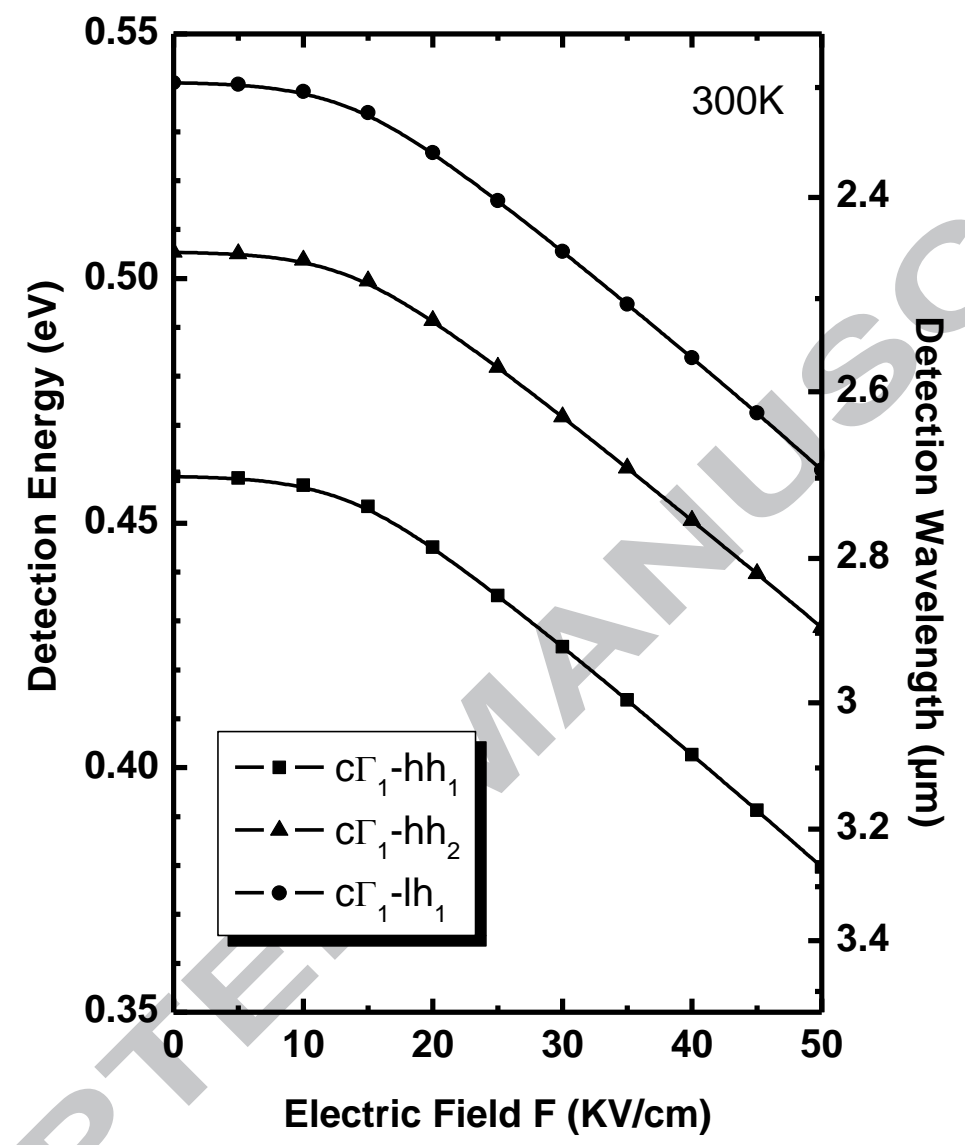


Figure 6

Detection Wavelength $(\mu \mathrm{m})$

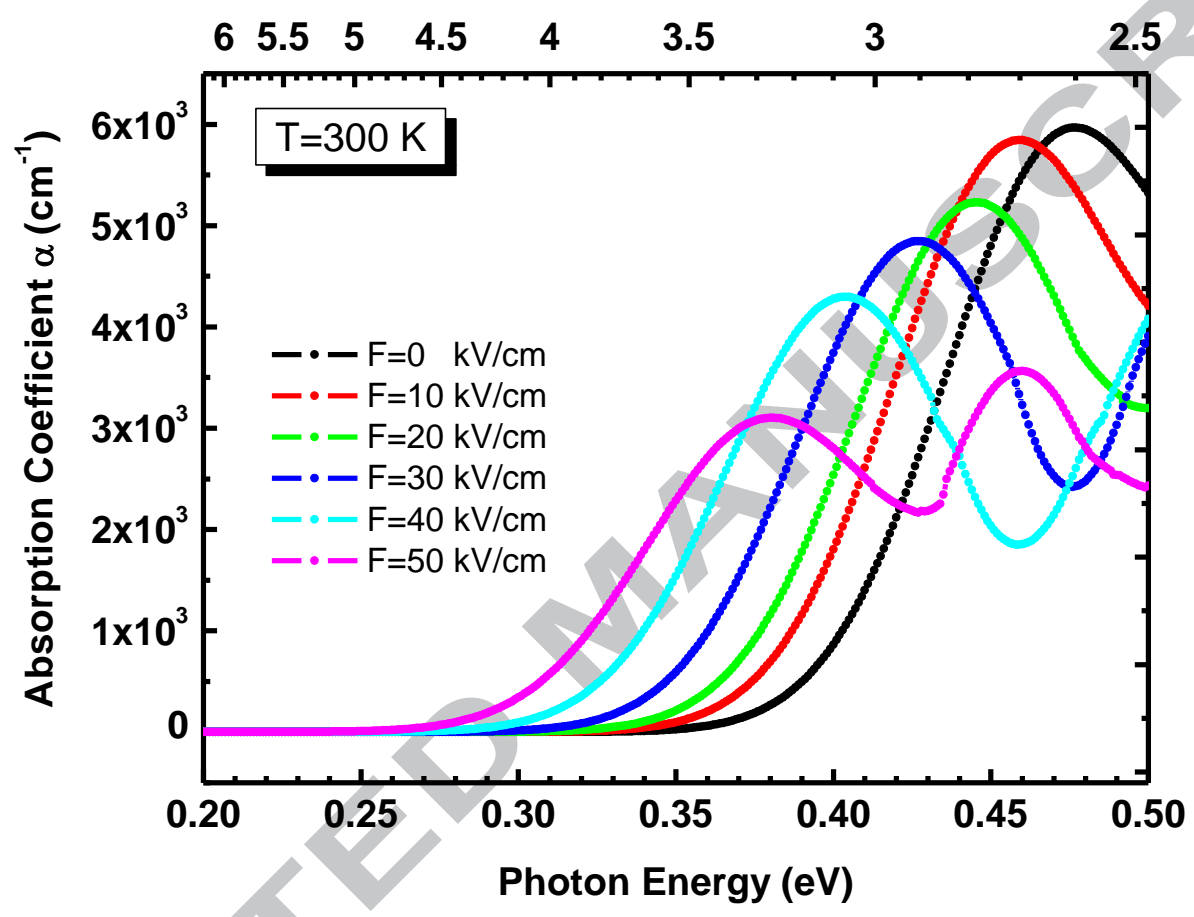




\begin{tabular}{|c|c|c|}
\hline Parameter & Ge & $\alpha-\mathbf{S n}$ \\
\hline $\mathrm{a}(\stackrel{\AA}{)}$ & 5.6573 & 6.4892 \\
\hline $\mathrm{E}_{\mathrm{g}}(\Gamma)(\mathrm{eV})$ & 0.798 & -0.413 \\
\hline $\mathrm{E}_{\mathrm{g}}(\mathrm{L})(\mathrm{eV})$ & 0.664 & 0.092 \\
\hline $\mathrm{E}_{\mathrm{v}, \mathrm{av}}(\mathrm{eV})$ & 0 & 0.69 \\
\hline$a_{c}(\Gamma)(e V)$ & -8.24 & -5.33 \\
\hline$a_{c}(L)(e V)$ & -1.54 & -0.342 \\
\hline $\mathrm{b}(\mathrm{eV})$ & -2.9 & -2.7 \\
\hline$\Delta_{0}(\mathrm{eV})$ & 0.30 & 0.80 \\
\hline $\mathrm{C}_{11}$ (in $10^{12}$ dyn $\left.\mathrm{cm}^{-2}\right)$ & 12.85 & 6.9 \\
\hline $\mathrm{C}_{12}$ (in $10^{12}$ dyn $\left.\mathrm{cm}^{-2}\right)$ & 4.83 & 2.9 \\
\hline$m_{c}\left(m_{0}\right)$ & 0.038 & -0.058 \\
\hline$m_{l, L}\left(m_{0}\right)$ & 1.57 & 0.4072 \\
\hline$m_{t, L}\left(m_{0}\right)$ & 0.0807 & 0.0204 \\
\hline
\end{tabular}

Table 1 


\section{Highlights}

- The electronic band parameters for heterointerfaces between strained $\mathrm{Ge}_{1-x} \mathrm{Sn}_{x}$ and relaxed $\mathrm{Ge}_{1-y} \mathrm{Sn}_{y}$ were calculated.

- The $\mathrm{Ge}_{1-\mathrm{x}} \mathrm{Sn}_{\mathrm{x}} / \mathrm{Ge}_{1-\mathrm{y}} \mathrm{Sn}_{\mathrm{y}}$ quantum well heterostructure was optimized in terms of compositions and thicknesses.

- The Stark effect on the absorption coefficient spectrum was investigated. 